\title{
Why and how to achieve total arterial revascularisation in coronary surgery
}

\author{
Alistair Royse ${ }^{1,2}$, Colin Royse ${ }^{1,2,3}$, Stuart Boggett ${ }^{1}$, Sandy Clarke-Errey ${ }^{4}, Z_{\text {Zulfayandi Pawanis }}^{5}$ \\ 'Department of Surgery, The University of Melbourne, Melbourne 3050, Australia. \\ ${ }^{2}$ Department of Cardiothoracic Surgery, Royal Melbourne Hospital, Melbourne 3050, Australia. \\ ${ }^{3}$ Outcomes Research Consortium, the Cleveland Clinic, Cleveland, OH 44195, USA. \\ ${ }^{4}$ Statistical Consulting Centre, The University of Melbourne, Melbourne 3050, Australia. \\ ${ }^{5}$ Department of Cardiothoracic Surgery, Universitas Airlangga, Surabaya 60132, Indonesia.
}

Correspondence to: Prof. Alistair Royse, Department of Surgery, The University of Melbourne, Melbourne 3050, Australia. E-mail: alistair.royse@unimelb.edu.au How to cite this article: Royse A, Royse C, Boggett S, Clarke-Errey S, Pawanis Z. Why and how to achieve total arterial
revascularisation in coronary surgery. Vesse/ Plus 2020;4:5. http://dx.doi.org/10.20517/2574-1209.2019.34

Received: 11 Dec 2019 First Decision: 3 Jan 2020 Revised: 16 Feb 2020 Accepted: 27 Feb 2020 Published: 13 Mar 2020

Science Editor: Mario F. L. Gaudino Copy Editor: Jing-Wen Zhang Production Editor: Jing Yu

\begin{abstract}
Single internal mammary artery and supplementary saphenous vein grafts (SVG) continues to be used in approximately $95 \%$ of coronary surgery as of 2019 . The late failure of SVG is very well documented yet remains the predominant conduit used - why? The left internal mammary artery almost never fails, and late angiography of patent radial artery grafts also appear entirely normal. Logic would suggest that avoiding the conduit known to progressively fail would lead to improved late outcome. Our studies have demonstrated such findings in large single centre and national registry datasets. We describe strategies to achievement of total arterial coronary revascularisation.
\end{abstract}

Keywords: Total arterial revascularisation, radial artery, total arterial revascularisation, radial artery, Y graft

\section{INTRODUCTION}

This paper is intended to be a pragmatic guide including diverse considerations related to the attainment of total arterial revascularisation. It is not a comprehensive review and limited discussion of some topics is intended to provide a summary of a topic rather than an exhaustive review of the topic.

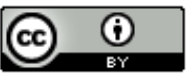

(C) The Author(s) 2020. Open Access This article is licensed under a Creative Commons Attribution 4.0 International License (https://creativecommons.org/licenses/by/4.0/), which permits unrestricted use, sharing, adaptation, distribution and reproduction in any medium or format, for any purpose, even commercially, as long as you give appropriate credit to the original author(s) and the source, provide a link to the Creative Commons license, and indicate if changes were made. 


\section{THE WHY: ACHIEVING TOTAL ARTERIAL REVASCULARISATION}

As of 2019, almost all cardiac surgeons perform 90\%-95\% of coronary bypass surgery (CABG) with the use of saphenous vein graft (SVG) worldwide ${ }^{[1,2]}$. Of the patients receiving total arterial revascularisation (TAR), a proportion will have been performed without specific strategic intent to achieve TAR [e.g., a single or double CABG using the internal mammary artery (IMA)]. Consequently, a deliberate strategy to achieve TAR in every patient is uncommon.

Consider the following proposition: if SVG develops atherosclerosis and fails - and that failure, then leads to the failure of the treatment of CABG - why is it that we count the number of arterial grafts?

\section{The argument in favour of counting veins rather than arteries}

"The LIMA-LAD is the only important graft in CABG"

The seminal publications of Lytle and Loop in the $1980 \mathrm{~s}^{[3-5]}$ reported data acquired during the 1970s, the period of IMA introduction. They found that use of left IMA (LIMA) significantly improved survival compared to exclusive use of SVG. The popular interpretation of these data over the following decades established the LIMA-LAD as somehow "sacrosanct". It should be borne in mind that LIMA was almost always the only arterial graft used, and the left anterior descending (LAD) almost always the only coronary target. All other targets including branches of the LAD were grafted with SVG. As of 2019, it is almost universally accepted that CABG is not of adequate quality if the LIMA-LAD is not used.

There are two apparent interpretations to the original papers by Lytle and Loop:

A. The IMA has "magical" properties which are impossible to define (not real, not scientific).

B. The observation arises from the difference between the late patency of an arterial graft compared to the late patency of a venous graft ${ }^{[3,6-14]}$.

Interpretation B is not popular with surgeons or cardiologists ${ }^{[3,15,16]}$, whilst Interpretation A is inconsistent with science or logic.

\section{Modes of conduit failure}

Progressive atherosclerosis of SVG is very widely documented with up to $50 \%$ of grafts occluding by about 10 years postoperative ${ }^{[8,17-19]}$. An angiographic classification was developed to categorise diseased SVG (see the work by Fitzgibbon ${ }^{[20]}$ ). At durations longer than 10 years, the progressive decline in SVG patency continues, although may be ameliorated with the widespread use of optimal medical therapies including statins $^{[21]}$.

It is widely accepted that the LIMA has a small early graft failure rate, considered to reflect flow competition from the native coronary circulation, and thereafter there is no clear evidence of any progressive conduit atherosclerosis as is the case for SVG. A LIMA which survives the early postoperative period is considered by most to be a "permanent graft" without prospects of progressive failure irrespective of the duration postoperative. The angiographic evidence in the late period supports this contention ${ }^{[22]}$. Indirectly, the greater survival of patients who have received LIMA grafts also supports this contention ${ }^{[23,24]}$.

For the LIMA, and most likely any IMA, the late angiographic findings are of: (1) patency (Patent); and (2) normal conduit lumen (Perfect Patency); or (3) Occluded/String sign. A string sign has not been well documented in the literature as being capable of reversal and is considered occluded (permanently). Thus, the angiographic findings are "binary" - Patent + Normal or occluded. Therefore, the Fitzgibbon classification is not suited to the use for this arterial conduit. A subtlety of complex arterial reconstructions is the variable diameter of an arterial conduit related to "autoregulation" of flow via changes to the diameter of the conduit. For example, the proximal segment of the LIMA in a composite graft such as LIMA-RA-Y 
Table 1. Patency and perfect patency for asymptomatic patients receiving conventional angiography $13 \pm 3$ years postoperative with at least one internal mammary artery, radial artery and saphenous vein graft

\begin{tabular}{lcccc}
\hline Comparison & Perfect patency $\boldsymbol{n}$ (\%) & $\boldsymbol{P}$ & Patency $\boldsymbol{n}$ (\%) & $\boldsymbol{P}$ \\
\hline IMA, RA, SVG & & $<0.001$ & & 0.015 \\
IMA vs. RA & $60 / 62(96.8)$ & 0.461 & $60 / 62(96.8)$ & 0.298 \\
& $71 / 77(92.2)$ & & $72 / 77(93.5)$ & 0.013 \\
IMA vs. SVG & $60 / 62(96.8)$ & $<0.001$ & $60 / 62(96.8)$ & 0.055 \\
& $10 / 57(17.5)$ & & $47 / 57(82.5)$ & 0.009 \\
RA vs. SVG & $71 / 77(92.2)$ & $<0.001$ & $72 / 77(93.5)$ & 0.009 \\
Arterial, SVG & $10 / 57(17.5)$ & & $47 / 57(82.5)$ & \\
Arterial vs. SVG & & & & \\
& $131 / 139(94.2)$ & $<0.001$ & $47 / 57(82.5)$ & \\
\hline
\end{tabular}

IMA: internal mammary artery; RA: radial artery; SVG: saphenous vein graft.

(RAY) or BIMA-Y (BIMAY) is usually larger in diameter proximal to the Y graft than distal to the Y graft, as it needs to be to provide additional flow to the second conduit as well as the continuation of the LIMA. These findings are normal and expected and do not represent a pathological state.

The most common alternative arterial conduit is the radial artery (RA) and, infrequently, the gastroepiploic artery (GEA). Controversy continues to surround the use of RA in CABG, its perioperative and intraoperative management and long-term outcomes. Data outcomes using statistics that estimate future events (Kaplan-Meier actuarial survival) suggest a progressive decline in patency of RA. This is discordant with the directly measured angiographic findings of RA, which are also "binary" - being either patent and normal or occluded/string sign. There are no serial angiographic reports in the literature of normal RA grafts in the early postoperative period, and then later developing progressive atherosclerosis and eventual occlusion. In our institutional experience of more than 20,000 RA use, we also have not documented progressive atherosclerosis leading to RA occlusion in serial angiograms. The longest duration postoperative for RA angiography in our experience is 22 years, whereby the RA appeared patent and normal.

In a research angiographic series we conducted with patients selected to have received all three IMA, RA and SVG conduits $(n=50)$ at $13 \pm 3$ years postoperative, we found that the Patency and Perfect Patency was the same for IMA $(97 \%, 97 \%)$ and almost the same for RA $(94 \%, 92 \%)$, respectively (one RA was diseased at the time of implantation, and remained patent and diseased). The patency of SVG was significantly lower $(83 \%)$ and the Perfect Patency of SVG was only 18\% [Table 1]. There were no significant differences in perfect patency or patency between IMA and RA, despite IMA being almost exclusively grafted to the LAD and RA being grafted to the other two territories.

The angiographic appearance of RA and IMA appeared to be the same in the late period and different to SVG indicating a different mode of graft failure.

\section{Predicting future failure of grafts}

It is understandable that a heavily diseased SVG may occlude in the foreseeable future - from logical first principles. Equally, a normal appearing arterial graft at angiography would suggest that this conduit is not likely to fail in the foreseeable future - from logical first principles. A further extension to the logical argument is that SVG is first exposed to the arterial blood pressure and flow rates on the day of surgery. These newly introduced factors may then lead to the development of accelerated atherosclerosis, which can be observed in the cardiac surgery, vascular surgery and renal access surgery domains. Arterial conduits have been exposed to the arterial blood pressure and flow since birth and should therefore not be expected to develop sudden or rapidly progressive atherosclerosis after being transplanted to the coronary circulation and being exposed to the same or similar blood pressure and high flow state. 


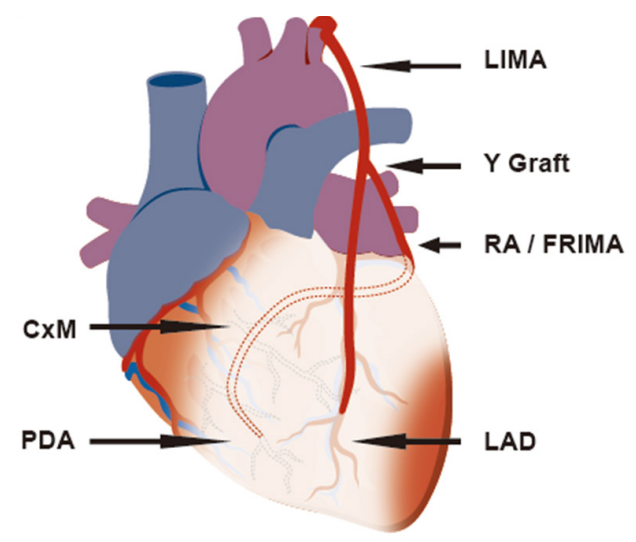

Figure 1. Schematic diagram of radial artery Y graft operation. LIMA: left internal mammary artery; RA: radial artery; LAD: left anterior descending artery; OM: obtuse marginal artery; PDA: posterior descending artery

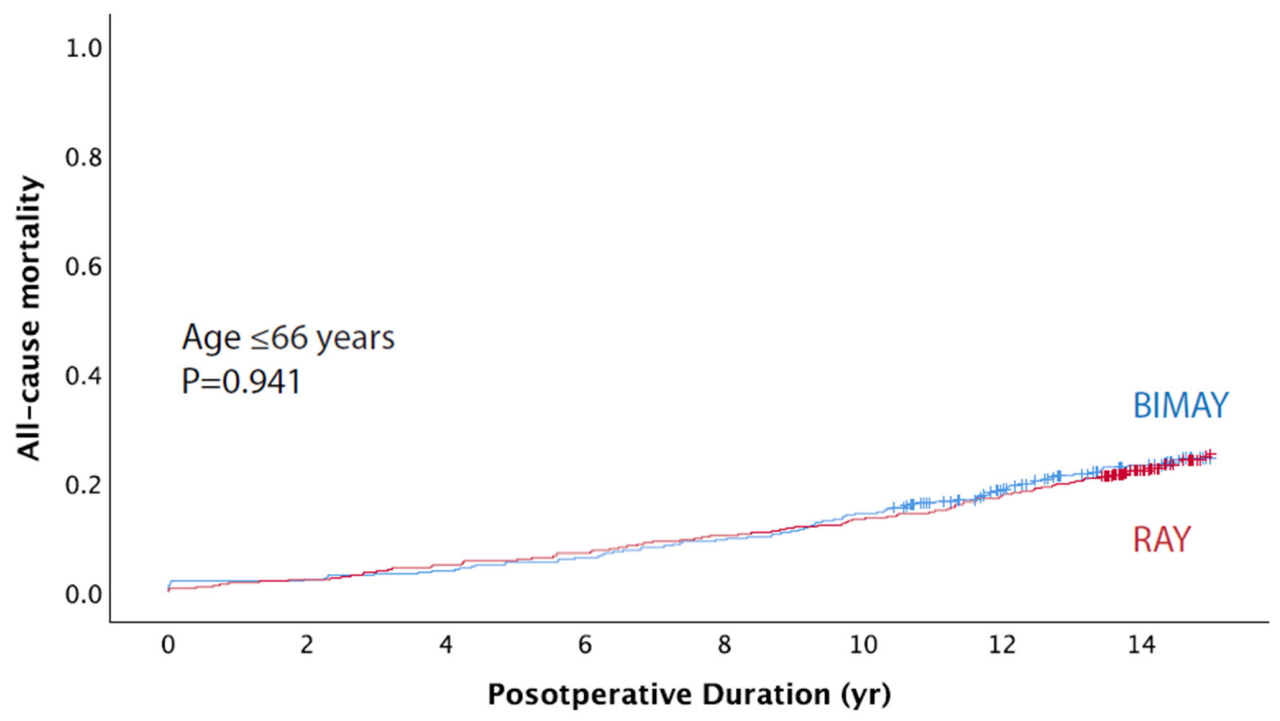

Figure 2. Mortality of propensity score matched cohorts of radial artery $Y$ graft versus bilateral internal mammary artery $Y$ graft operations, $n=371$ pairs. RAY: radial artery $Y$ graft; BIMAY: bilateral internal mammary artery $Y$ graft

\section{All-cause mortality as a surrogate for coronary graft failure}

In large-scale randomised or very well-matched series, it is expected that the non-cardiac cause of death will be equally distributed between groups. For a revascularisation procedure such as CABG, it would be expected that non-coronary causes of cardiac death such as progressive native valve disease would also be equally distributed between groups. Hence, excess mortality is considered to be caused by graft failure, which leads to ischaemic complications that may lead to premature death ${ }^{[7,25]}$.

\section{Could IMA and RA be similar?}

In a series of composite arterial grafted patient (Y graft) [Figure 1] to all three coronary territories and closely propensity score matched, we compared bilateral internal mammary artery Y graft (BIMAY) and radial artery Y graft (RAY) in the Australian population [Figure 2]. All-cause mortality was measured by the national death register and is considered robust. Comparing single surgeon experience from Sydney and an institutional experience from Melbourne, we found no difference in mortality between the two techniques for age at surgery ( $\leq 66$ years, $P=0.941$, Figure 2 ) or when all ages were included (due to a severe age distribution imbalance, $P=0.239)$. 


\section{Equivalence of arterial conduits?}

There is considerable theoretical or in vitro evidence to suggest that the LIMA has properties that renders it "superior". These are claimed to include increased synthesis of nitric oxide, resistance of smooth muscle cells to proliferation, tight endothelial junctions, decreased expression of adhesion molecules and other theoretical correlations between histological structure and long-term function ${ }^{[26-29]}$. The discussion, however, has mainly been confined to the comparison with SVG, where the RA is considered to have a thicker muscular layer and in vitro and in vivo experimentation suggests that it is prone to spasm and theoretically more likely to develop atherosclerosis ${ }^{[30-36]}$.

However, direct observation suggests otherwise. Consider the following propositions:

1. If a 75-year-old patient had a LIMA, RA and GEA harvested, and all were normal - why should they be so (given that the popular belief that only the LIMA is especially resistant to the development of atherosclerosis)? Specifically, all conduits have been exposed to the arterial blood pressure and flow for 75 years prior to harvest - and are normal - suggesting that all three behave similarly.

2. Angiograms of patent arterial conduits more than 10 or 20 years postoperative reveal a "binary" outcome. Either the conduit is Patent + Normal or Occluded/String sign. These findings are the same for all arterial conduits. Specifically, all conduits are exposed to the arterial blood pressure and flow postoperatively - and remain normal - suggesting that all three behave similarly.

3. If a length of artery remains normal whilst in the arterial circulation for decades prior to surgery why should it suddenly develop atherosclerosis within a few years of being transplanted into the arterial circulation of the heart (when it is exposed to the same blood pressure and flow as pre-harvest)? Specifically, the haemodynamics of the coronary circulation are essentially the same as for the chest wall, forearm or stomach and there is no credible reason to expect that an arterial conduit will alter its behaviour merely upon use as a coronary graft.

How should the many theoretically- or laboratory experiment-based predictions as to the short- and longterm behaviour of various arterial conduits which conflict with direct observations be interpreted? In the view of the authors, direct observation overrides theoretical- or laboratory-based conclusions, and suggest that further refinement of both theory and interpretation of experimentation is required.

It is suggested that there is a striking similarity for all arterial conduits used in coronary surgery, and, if they do not fail early due to competitive flow, they may be expected to remain patent. All behave differently to SVG, giving rise to the saying, "arteries are arteries - and veins are not". Should all arterial conduits be considered as interchangeable - would it be acceptable to use RA or GEA to graft the LAD? This is the position that the authors now accept as valid. Please refer to Part 2 for why widespread adoption of this concept is not likely to be rapid.

\section{Complete revascularisation}

The consideration of incomplete revascularisation relates primarily to a difference in strategy between PCI, where treatment of the "culprit lesion" is preferred (at least in the acute setting), and the usual surgical strategy of full revascularisation with CABG. Within CABG, off pump CABG has been associated with few grafts, suggesting that incomplete revascularisation is more common, which may impact on outcome. This is beyond the scope of this paper and for the remainder of this paper it is assumed that all patients received full revascularisation.

Could RAY and TAR achieved by any other reconstruction technique be similar?

In a large institutional cohort, we demonstrated that the survival of RAY and TAR by other techniques was not different $\left(P=1.000^{[37]}\right.$, Figure 3). 


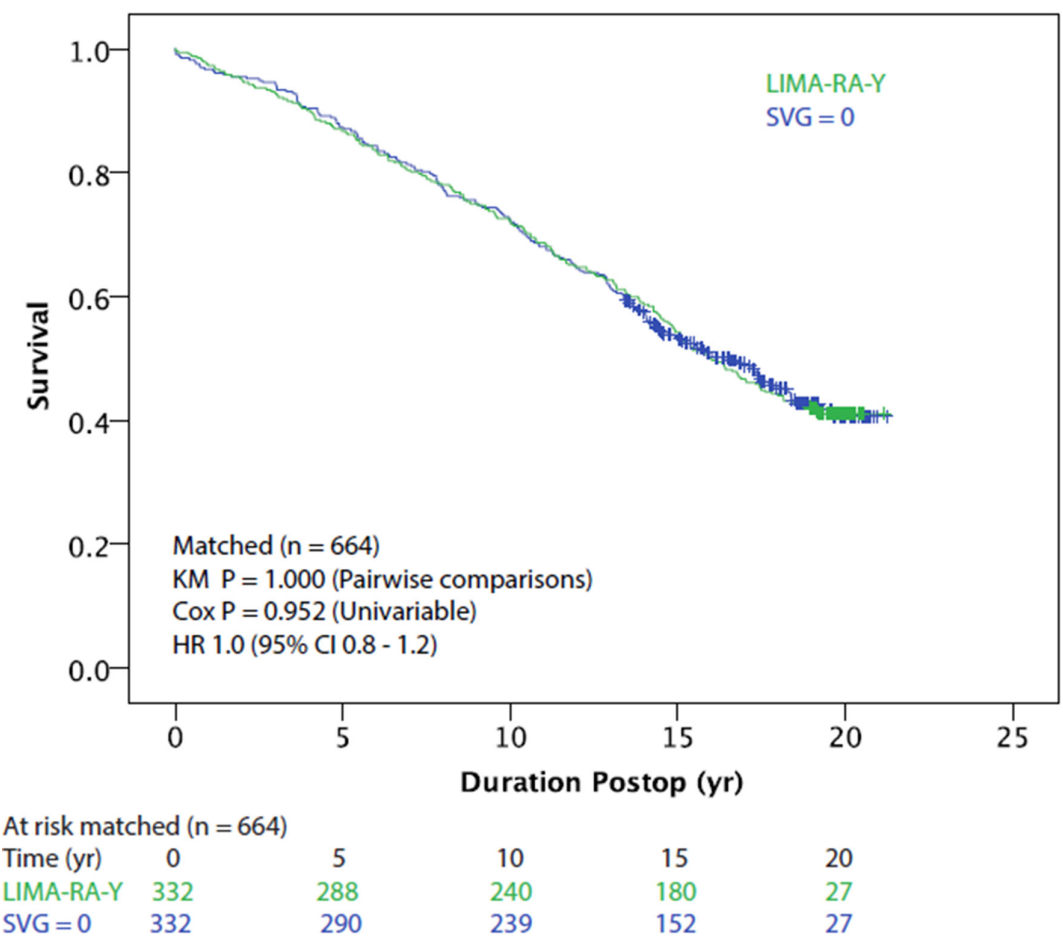

Figure 3. Survival of propensity score matched radial artery $Y$ graft versus total arterial revascularisation patients by any other reconstruction technique, $n=332$ pairs. Reproduced with permission, JACC 2018 ${ }^{[37]}$. LIMA-RA-Y: left internal mammary artery radial artery Y graft; TAR: total arterial revascularisation

Is RAY or TAR survival significantly better than single internal mammary artery and saphenous vein graft?

We demonstrated that the survival of the "conventional CABG" of left internal mammary artery and supplementary saphenous vein graft (LIMA + SVG) was significantly lower (HR 1.3 95\%CI: 1.0-1.6, $P=$ $0.043^{[37]}$, Figure 4).

Is multi-arterial grafting significantly better than single IMA + SVG?

The theoretical framework is that, if one arterial graft is better than SVG, then two or even three arterial grafts should have incrementally greater survival, and this contention is supported by multiple publications ${ }^{[38-40]}$. In our own national database analysis, we conducted a series of large-scale propensity score matches using 17 variables. One arterial graft with supplementary SVG (1A + SVG) was compared to $2 \mathrm{~A}+\mathrm{SVG}(n=7895$ pairs $)$ with a mortality hazard in favour of more arterial conduits of 1.21 (95\%CI: 1.12$1.30, P<0.001)$. For the comparison of $3 \mathrm{~A}+\mathrm{SVG}(n=3017$ pairs $)$, the mortality hazard in favour of more arteries was 1.41 (95\%CI: $1.24-1.60, P<0.001)$. Our findings are consistent with the literature and with greater sample size.

The 10-year Arterial Revascularisation Trial outcome remains highly controversial and variously claimed to support the lack of evidence for two IMA leading to improved late survival as would otherwise be predicted by the evidence presented earlier ${ }^{[4]}$. Clarity of interpretation is gained by understanding the key confounders and thereby discounting the "as randomised" (intention-to-treat) analysis in favour of the "as treated" analysis. The all-cause mortality was not different for those randomised to one or two IMA ( $P=$ $0.62)$.

One key weakness of the study design was to allow use of RA without consequence - this was consistent with the popular belief at the time of study design - that RA was perhaps "no better" than SVG. Although this view remains commonplace to this day, the evidence is that RA has superior angiographic, clinical and 


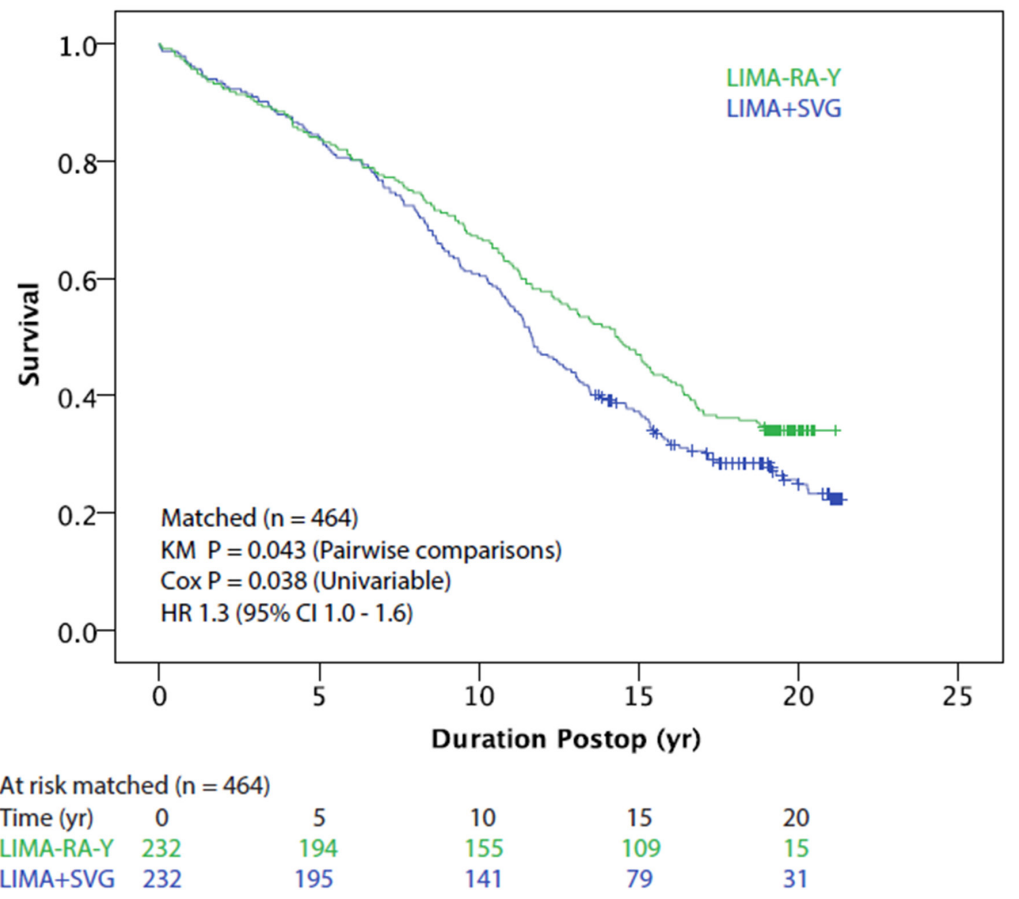

Figure 4. Survival of propensity score matched radial artery $Y$ graft versus left internal mammary artery and supplementary saphenous vein graft patients, $n=332$ pairs. Reproduced with permission, JACC $2018^{[37]}$. LIMA-RA-Y: left internal mammary artery radial artery $Y$ graft; LIMA + SVG: left internal mammary artery and supplementary saphenous vein graft

survival outcomes compared to $\mathrm{SVG}^{[37,40,42-44]}$. Therefore, the study design of one versus two IMA, rather than one versus two arterial grafts was confounded by RA being used. Additionally, there was a high crossover from the randomised allocation. For patients randomised to one IMA, RA was used in $22 \%$ and BIMA used in $4 \%$ resulting in $26 \%$ receiving more than one arterial graft. Additionally, of patients randomised to two IMA, $14 \%$ crossed over to a single IMA, resulting in a $40 \%$ crossover rate of one versus two arterial grafts. It was not reported how many patients randomised to BIMA received additional RA grafts, which could potentially further magnify the groups discrepancy. By contrast, the post-hoc (non-randomised) dataset analysed all-cause mortality according to the use of 1 or $\geq 2$ arterial grafts and found a significant survival advantage for more arterial grafts (HR 0.81, 95\%CI: 0.68-0.95). Criticism of post-hoc nonrandomised data is reasonable and valid.

However, this argument misses an even more important consideration of this dataset, which is that both groups in either of these analyses include supplementary SVG. If SVG is the conduit known to progressively fail and leads to ischemic events, of which some lead to death (see below), then the two groups remain relatively similar because both groups still use SVG. Specifically, SVG is more important in the causation of failure of CABG than the arterial grafts, in the long term. A further analysis of this dataset according to TAR $v s . \geq 1$ SVG has not been published.

"The chicken and the egg" dilemma

The obvious consequence of increasing use of arterial grafts is that there is a compensatory reduction in the number of SVG being used. We conducted an analysis whereby the number of grafts was restricted and then performed separate matching for all grafting combinations within each stratum ${ }^{[42]}$ [Figure 5]. For each stratum, the increasing use of SVG (and reduction in the use of arterial grafts) resulted in an increasing mortality hazard. 


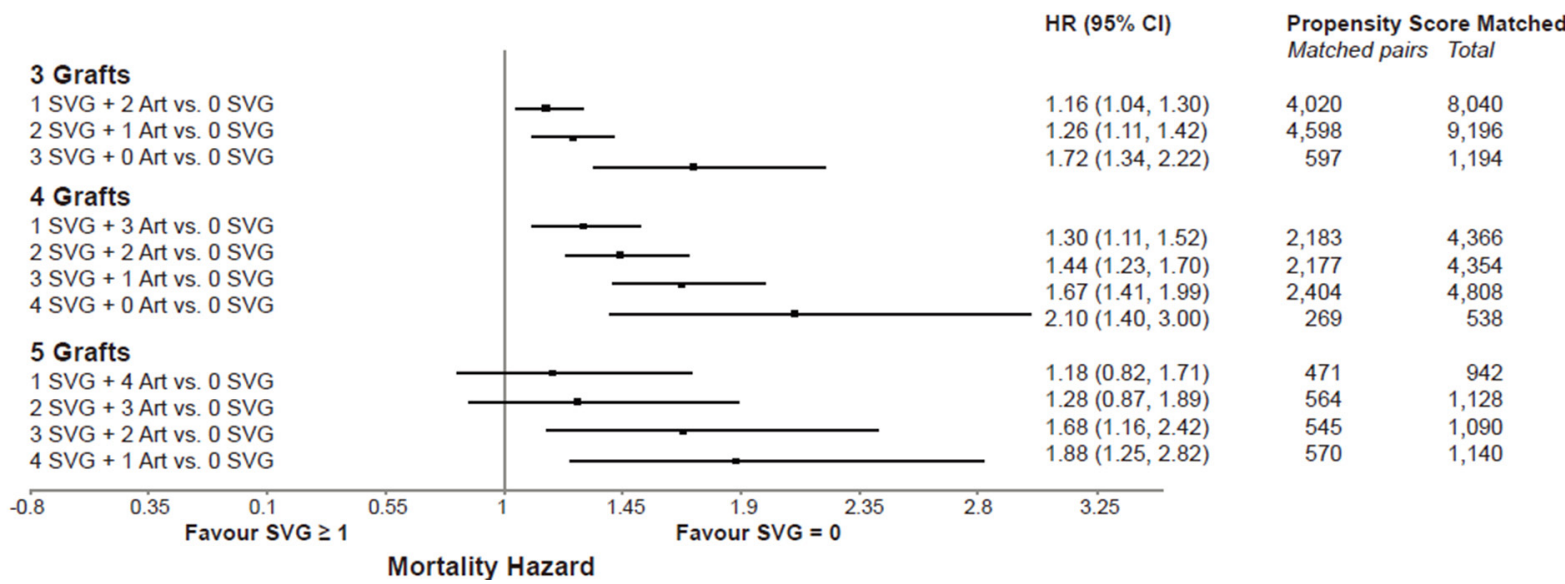

Figure 5. Multiple propensity score matched analysis according to increasing saphenous vein graft use within restricted number of grafts. Reproduced with permission EJCTS $2018^{[42]}$. SVG: saphenous vein graft; Art: arterial grafts; O SVG or SVG = 0, total arterial revascularisation

\section{Count the veins, not the arteries}

We know that SVG will develop progressive atherosclerosis and progressively fail in the long term. We know that, except for a small percentage of arterial grafts failing in the short term due to flow competition from the native coronary circulation, there is a paucity of evidence to suggest that arterial grafts will ever progressively fail in the long term. Survival with one or more SVG was lower than for TAR [Figure 6]. The survival advantage of TAR remained even when there was a majority of grafts that were arterial (multiarterial) and with one $\mathrm{SVG}^{[42]}$ [Figure 7].

The relationship between graft failure and reduced survival has a plausible mechanism and therefore it is suggested that the conduit of most interest is the SVG rather than the arterial conduits ${ }^{[37,38,40,45,46]}$. It would be logical, therefore, that the number of SVG grafts has greater effect on survival than the number of arterial grafts. The strategy of TAR is predicated on the principle of reducing or eliminating SVG grafts, rather than the principle of greater number of arterial grafts.

\section{Early mortality of TAR}

Whilst it is a common belief that TAR is more complex and therefore results in a higher perioperative mortality, there appears to be very little evidence to support this view. Indeed, the evidence points to a lower perioperative mortality with $\operatorname{TAR}^{[47-49]}$. There is also a paucity of evidence that "low volume" centres exhibit a disproportionally higher perioperative mortality with TAR; indeed, the same argument was present in the 1980s and 1990s when there was resistance to the increased use of IMA ${ }^{[46,50-52]}$.

\section{Potential risks of multi-arterial grafting}

The principle risk of BIMA is a higher rate of deep sternal wound infection. The literature is vast with considerable debate; however, large-scale or meta-analyses indicate a consistent finding that the rate is approximately double that of single IMA, higher in diabetics and obese females and possibly lower with skeletonised $\mathrm{IMA}^{[53-56]}$. Logically, harvesting the IMA by any method substantially reduces the blood supply to one side of the sternum, and any difference between harvest techniques is not likely to be substantial.

The risks to the forearm following RA harvest are surprisingly low ${ }^{[57-61]}$. Ischemic complications affecting the hand are exceptionally rare. Wound infections are infrequent due to the superior blood supply of the forearm relative to the leg, and nerve damage is confined to local nerves that are entirely cutaneous and which do not supply the palm or fingertips. There is no evidence that the forearm has reduced blood flow following RA harvest ${ }^{[62]}$. 


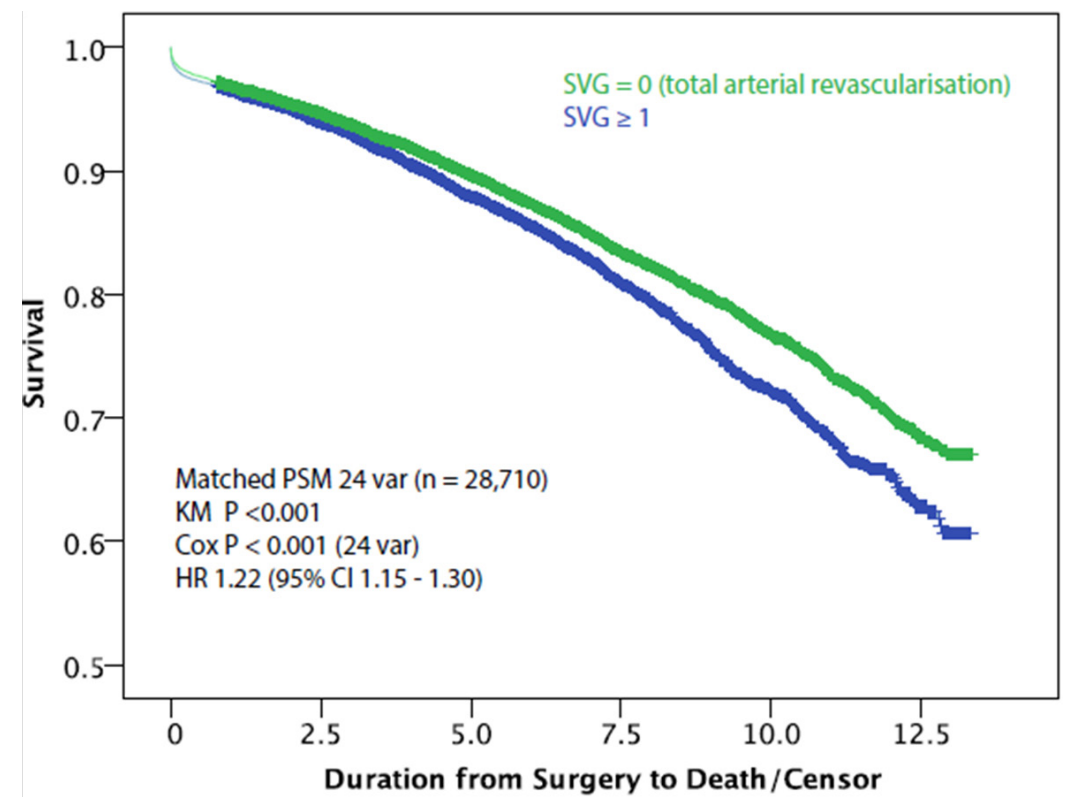

At risk matched $(n=28,710)$

$\begin{array}{lcccccc}\text { At risk matched }(\mathrm{n}=28,710) & & & & & \\ \text { Time }(\mathrm{yr}) & 0 & 2.5 & 5.0 & 7.5 & 10.0 & 12.5 \\ \text { SVG }=0 & 14,355 & 11,320 & 7,846 & 4,955 & 2,711 & 591 \\ \text { SVG } \geq 1 & 14,355 & 9,866 & 5,255 & 2,158 & 874 & 153\end{array}$

Figure 6. Propensity score matched comparison of total arterial revascularisation and the use of one or more saphenous vein grafts, $n=14,355$ pairs. Reproduced with permission EJCTS 2018 ${ }^{[42]}$. SVG $=0$, total arterial revascularisation; SVG $\geq 1$, use of one or more saphenous vein grafts irrespective of the number of arterial grafts; KM: Kaplan-Meier; Cox: Cox proportional hazards method; HR: hazard ratio; 95\% Cl: 95\% confidence interval; SVG: saphenous vein graft

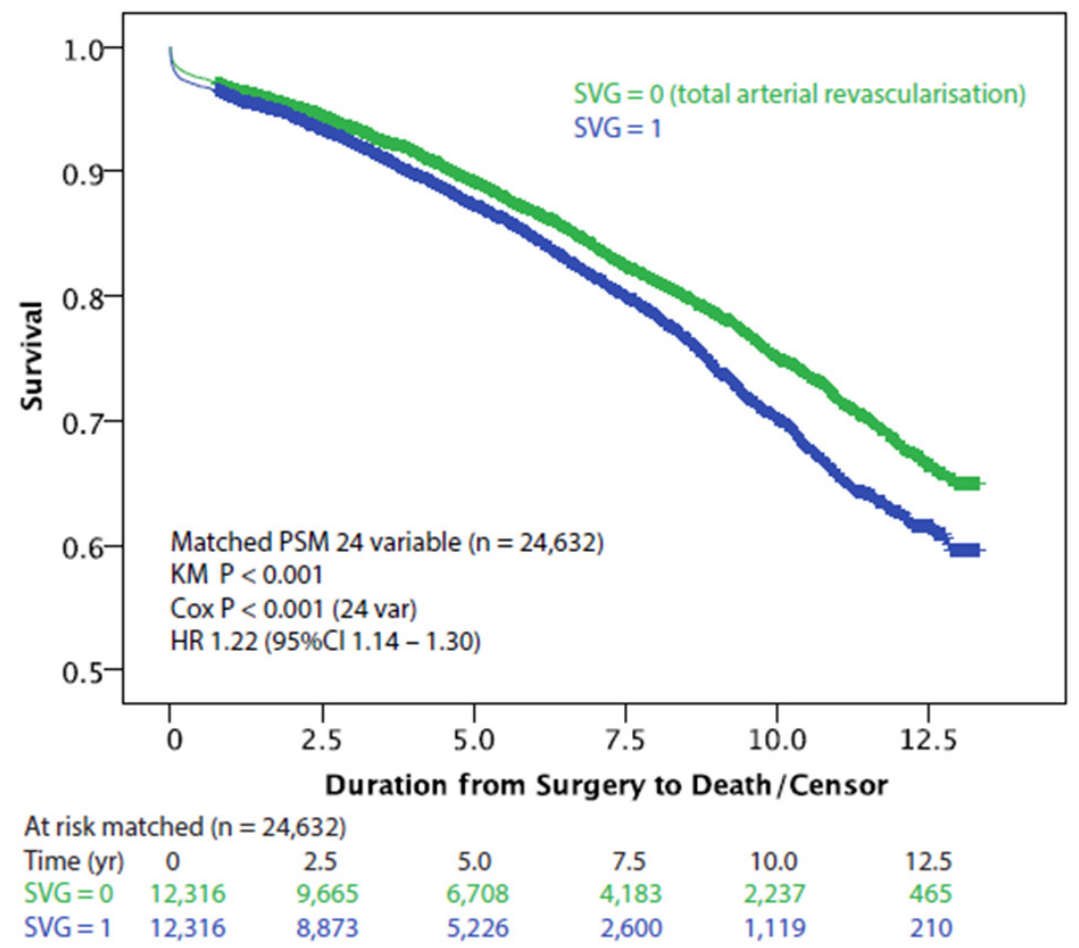

Figure 7. Propensity score matched comparison of total arterial revascularisation and the use of one or more saphenous vein grafts, $n=$ 12,316 pairs. Reproduced with permission EJCTS $2018^{[42]}$. SVG $=0$, total arterial revascularisation; SVG $=1$, use of one single saphenous vein graft irrespective of the number of arterial grafts (number of arterial grafts $1.7 \pm 1.1$ ); KM: Kaplan-Meier; Cox: Cox proportional hazards method; HR: hazard ratio; 95\% Cl: 95\% confidence interval; SVG: saphenous vein graft 
The key perioperative risks relate to end-organ dysfunction due to iatrogenic systemic hypotension leading to end organ hypoperfusion. Acar first advanced the hypothesis that RA was prone to spasm that could be managed by intravenous vasodilators ${ }^{[63]}$. The media of RA is thicker than for IMA, and the logic that RA appeared likely to be prone to spasm gained momentum, resulting in a widespread use of vasodilators only when RA was used. This continues in most centres today, resulting in early abandonment of RA use. Remarkably, there has been no large-scale study undertaken to date. Two small randomised controlled trials (RCT) failed to show benefit for vasodilators, but they were criticised for lack of power ${ }^{[64,65]}$. In a metaanalysis of six RA RCTs, benefit for vasodilators was found ${ }^{[66]}$, but caution in interpretation was advised ${ }^{[67]}$. This author has used vasoconstrictors in the majority of patients since 1996, and 100\% of patients since 2008 including all patients where RA was used. The author observes that RA spasm is less severe and less frequent than for IMA.

A theoretical risk for composite grafting is a poorly constructed $\mathrm{Y}$ anastomosis, which could compromise one or both of the conduit limbs distal to the Y graft. However, there are no reports that relate specifically to this risk. It is assumed that the patency of both limbs is primarily dependent on the integrity of the conduits and flow dynamics affecting the distal anastomoses. The influence of competitive flow has been suggested to influence composite grafts to a greater extent than aorta-coronary grafts ${ }^{[68-70]}$; however, the bulk of the literature would suggest that the outcomes are similar ${ }^{[71-76]}$.

The relationship between surgeon or institutional operative volume and mortality or other outcomes is generally strongly held. There is some evidence from the surgical literature (often not relating to CABG) that lower volume equates with higher mortality or adverse outcome ${ }^{[77-80]}$, whereas other studies found no such relationship ${ }^{[81,82]}$. For the Royal Melbourne experience, the mortality of CABG when routine TAR was adopted was lower ${ }^{[83]}$, and mortality is lower or similar in many reports ${ }^{[52,84-89]}$.

However, this argument misses the point of change in CABG practice. In the examples above, mostly the analysis relates to performance of a procedure in sufficient volume (or not performing the procedure insufficient volume). In the case of CABG using more arterial conduits, there is usually no change to the number of cases performed or the reconstruction methods used. Thus, the central consideration relates to a minor change in practice rather than a consideration of the volume of cases. Specifically, the number of CABG cases for each surgeon or institution, the number and distribution of grafts, the management of cardiopulmonary bypass, and for the most part the postoperative management of the patient will all remain the same. The differences in operative technique for the harvest of arterial rather than venous conduit, the anastomosis suture technique and any other aspect of the surgical procedure are minor. It is a common view, therefore, that that differences between non-complex arterial reconstructions and conventional surgery are greatly exaggerated. The adoption of TAR represents a relatively small and easily managed alteration to the operative technique.

\section{PSYCHOLOGICAL BARRIERS TO ACHIEVING TOTAL ARTERIAL REVASCULARISATION - THE KEY BARRIERS}

\section{The conformist pressure}

A remarkably powerful force in medicine is the desire of a group to be homogenous or at least in conformity with the leader of the group. In addition, since the cardiac surgeon is dependent on the cardiologist for patient referrals (but the cardiologist is not dependent on the surgeon for referrals), many surgeons are conscious of the need to ensure that their referring cardiologists prefers greater use of arterial grafts - before the surgeon changes their technique. In practice, there is often a misalignment between cardiologist and surgeon which results in maintenance of the status quo. 
Complications occur in all medical treatments, but, when new techniques are introduced, there is often a new benchmark established by those resisting change - that of a zero tolerance of complications, different from normal practice of an acceptable rate of complications as dictated by local guidelines, societies or the literature. This practice leads to excessive psychological stress on the surgeon attempting the change, often leading to return to the status quo (the intent of the criticism).

Guidelines are the result of a consultative and consensus opinion of experts reviewing the existing literature. Level A evidence always relates to techniques that have been in use for a long time, usually decades. The key intended effect of guidelines is to enforce conformity: for those whose practice lags behind the mainstream to update to the mainstream practice as well as for pioneers and early adopters of new techniques to return to the mainstream. "Evidence-based medicine" usually refers to conformity to guidelines, increasing the risk to the individual practitioner if they practice outside of the guidelines; hence, risk aversion is a powerful force acting against new change.

\section{Technical difficulty of grafting}

The technical difficulty is usually exaggerated. Coronary surgery is fairly basic conceptually and most surgeons are competent at suturing a conduit to a target coronary artery.

The simple path to evolve practice is to substitute an arterial conduit for a venous conduit - and not to change any other aspect of the surgical technique. By the use of both IMAs and both RAs, four grafts can be easily achieved without alteration of the surgeon's usual operative routine. In this way, the majority of CABG could achieve TAR and the remainder of the patients could receive multi-arterial grafting. This change in practice is simple and easily achievable, with minimal risk to the surgeon's reputation and results but with long-term survival benefit to the patient.

To achieve routine TAR or at least high rates of TAR does require the use of more complex reconstructive techniques, which are discussed below, and it is recommended that surgeons who rarely perform TAR commence with substituting arterial conduits in the first instance before attempting more complex methods.

\section{The "R" word}

Surgeons who infrequently use a RA will usually articulate that the late outcomes of RA are:

(1) "no good";

(2) RA is difficult to harvest and their assistants are untrained;

(3) RA takes too much time to harvest and they cannot afford the time; or

(4) they have to introduce the use of vasodilators to their practice due to the reports of the high tendency of RA to spasm, which may then introduce iatrogenic complications related to low blood pressure and reduced end organ perfusion.

The use of RA is integral to the achievement of TAR for most surgeons (although a BIMAY technique could be an alternative). In our Australian series, RA represented $47 \%$ of all grafts in the TAR group and $25 \%$ in the Multi-Arterial Grafting (MAG) group prior to propensity score matching. Our group has a large experience of RA use and considers:

(1) RA exhibits late angiographic patency very similar to IMA - a patent graft in the short term appears to remain patent and normal in the long term. This contributes to the TAR group maintaining the highest late survival, as well as to survival in the MAG group exceeding $1 \mathrm{~A}+\mathrm{SVG}$. The in-hospital mortality is not increased in our experience.

(2) RA is the simplest conduit to harvest, and substantially easier than IMA. It is also the easiest harvest technique to learn. We harvest RA with similar technique methods as for IMA: enter the correct anatomical 
plane (within the fascia surrounding the neurovascular bundle), dissect the tissues with low power electrocautery, divide the branches between two small metal clips with electro-cautery and retain the satellite veins. Alternatively, use of scissors or an ultrasonic scalpel is also very safe. Topical and intraluminal $1 \%$ papaverine is used.

(3) Harvest of the RA is faster than for IMA and similar to or faster than SVG.

(4) RA is less prone to intraoperative spasm requiring topical therapy than IMA.

(5) For more than two decades, our institution has liberally used intermittent and/or continuous intravenous vasoconstrictors to maintain physiological blood pressure (usually $>100 \mathrm{mmHg}$ systolic) in order to maintain end organ perfusion (including cardiac graft perfusion). In the case of these authors, since $2008,100 \%$ of all cardiac operations have had a low dose of norepinephrine commence at the start of the anaesthetic and continued throughout the operation and into the ICU period - sometimes for days. In the case of a severe systemic inflammatory response syndrome, the infusion may be substantially increased even to $50 \mu \mathrm{g} / \mathrm{min}$. We have not observed RA spasm clinically, and, rarely when a patient undergoes perioperative angiography, we have not documented RA spasm. We do not use intraoperative calcium channel blocking agents and there is a highly variable use of these agents postoperatively with poor compliance on follow up. We therefore advocate that surgeons using RA for the first time or infrequent users of RA should not vary their intraoperative or postoperative management from their usual practice and not make any adjustments to their usual blood pressure guidelines or to the drugs that they normally use.

(6) RA is longer than IMA.

(7) RA is larger and more robust, making anastomosis construction easier than for IMA.

(8) RA is less prone to kinking than SVG.

\section{Cognitive dissonance}

Leon Festinger was a New York born social psychologist, who published the Theory of Cognitive Dissonance ${ }^{[0,91]}$. This wide-ranging theory has some applicability to cardiac surgery.

Consider: Example from the theory: a smoker, who knows that smoking is harmful and that he should stop, continues to smoke. Why?

The theory explains that the desire to smoke conflicts with the desire to be healthy, resulting in internal psychological tension (dissonance) and they will take steps to try and reduce this tension. For example, they may rationalise their behaviour, excuse it, blame others, deny it, etc. However, a further facet of the theory is that, if another person were to try and persuade them to stop smoking, or even blame them for smoking, then they will vigorously defend their right/desire/intent to keep smoking. That is, the help offered is frequently seen as more threatening to their sense of self than is their own internal conflict on the same subject.

Example from cardiac surgery: a cardiac surgeon, who believes that SVG will ultimately fail and would prefer to use more arterial grafts but continues to use SVG.

\section{THE HOW: PRACTICAL STEPS TO BECOME A ROUTINE TAR SURGEON}

\section{Keys to success}

1. It is relatively easy and safe to become a "mostly" TAR surgeon.

2. Stage the introduction of more complex techniques and become comfortable with them before proceeding. 


\section{Radial artery harvest}

The key to simple RA harvest is to enter the correct anatomical plane, which is within the fascia immediately surrounding the superficial radial nerve, radial artery and veins. Here, the RA lies in loose areolar tissue and can be harvested with its two satellite veins with the minimum of dissection.

Tips: Please do not include surrounding tissues such as additional deep fascia, muscle or tendon fragments, as this increases the trauma to the forearm without benefit. Specifically, such a harvest has no advantage for influencing spasm.

An alternative is endoscopic harvest of RA and it is not recommended that this technique is used in the initial experience. The open technique will provide for a clear understanding of the anatomy and minimise any risk to the RA or forearm structures [Video 1].

Tips: Division of the proximal end of RA can be undertaken with metal clips or suture ligation (the latter recommended in the initial experience). No separation of the satellite veins from the RA should be performed prior to proximal division, as this often causes spasm of the proximal $1 \mathrm{~cm}$ of RA. However, separation of the veins after division does not cause spasm, and the reason for this is not apparent. Generally, spasm is less common or severe than that seen in the distal segment of the IMA and treatment is the same, with use of papaverine and rarely use of a metal probe.

RA may be stored with the usual preparation used by the surgeon for IMA. The author uses $1 \%$ papaverine with heparin and no blood, whereas others may dilute the solution with some blood of similar volume. There is no convincing evidence of efficacy superiority for any method.

\section{Grafting aorta-coronary with radial artery (keep it simple)}

Using the same suture technique and suture material, as is the normal practice of the surgeon when grafting with SVG, should result in the same technical result as is their usual practice.

Tips: The RA is easier to use than SVG as it has a thicker wall and is more elastic and so less prone to kinking if it is of redundant length. A minor technique difference of the distal anastomosis is that the RA does not require the construction of a "hood". For SVG to adopt a satisfactory lie without flattening over the toe (distal) region of the anastomosis, it is common for surgeons to leave some of the SVG redundant so that a rounded "hood" is created. This occurs when the conduit anastomosis area is larger than the coronary anastomosis area. This is not necessary for all arterial conduits, and exact size matching is preferred and does not ever lead to restriction at the anastomosis.

The proximal anastomosis to the aorta is constructed as for an SVG anastomosis with the same suture materials (e.g., $6 \mathrm{O}$ Prolene). No SVG intermediary hood between the aorta and the RA, or any alternative anastomosis method, is required.

\section{Sequential grafting}

The rationale for single SVG conduits per distal coronary anastomosis arose from the experience gained during the 1970s. It was common to use a single length of SVG to commence at the aorta and then graft all distal targets with sequential anastomoses - the so-called "round the world" graft. Since the most common site of SVG graft failure was near to the aortic anastomosis, the danger was that all grafts would fail simultaneously, leading to large ischemic implications. The strategy of a separate conduit for each anastomosis was therefore a strategy of limiting the impact of SVG graft failure to just one target anastomosis. Sequential grafting therefore fell out of favour. 
In the era of arterial grafting, sequential grafting is essential to maximise the efficient use of conduit. The underlying premise is that arterial conduits will remain patent in the long term, distinct from the SVG experience.

A wide variety of sequential anastomosis techniques has been described ${ }^{[92-95]}$, but we describe a simple and pragmatic approach in this section. The conduit is then draped over the coronary artery at whatever angle appears to offer the best "lie" without tension. This may vary from directly overlying ("parallel"), to crossing at right angles ("diamond") or somewhere in between ("oblique"). An incision is made longitudinally in both coronary artery and conduit of equal size. If the first suture placed passes through the native coronary artery at a point where the heel of the conduit would lie, and the second needle is then used to pass through the conduit at the heel, this angle is preserved. The anastomosis may then be completed with whatever usual suture method is preferred by the surgeon.

Tips: Arterial conduits may be constructed with parallel or oblique anastomoses due to the ability of the arterial conduit to adopt curves with redundant length of conduit as they are not prone to kinking. However, the SVG is very prone to kinking and it is essential for most sequential anastomoses that it be constructed to prevent any curvature to SVG, which usually results in the lie of the SVG and the coronary target being at right angles to each other - the diamond anastomosis.

Tips: It is generally easier to construct sequential anastomoses along the length of the conduit from its proximal to distal end, as this facilitates the movement of the free distal end of the conduit during suturing. Consideration should be made to creating the aortic anastomosis first, followed by sequential grafting along the length of the conduit as required.

\section{Y (composite) grafting}

The key elements of Y grafting are established by the techniques already described ${ }^{[95-99]}$. Use of RAY where the LIMA and left RA are harvested simultaneously results in no prolongation of the operation over usual practice and additionally may be useful if the right RA has been used to perform diagnostic coronary angiography.

To perform the Y anastomosis, place two folded gauze over the distal ascending aorta after division of the thymus. This stabilises the movement from the heart facilitating suturing. At the level of the inferior aspect of the brachiocephalic vein, make a longitudinal incision on the chest wall aspect of the LIMA approximately 50\% longer than for the LAD anastomosis. The proximal end of the RA [or free right internal mammary artery (RIMA)] is then sutured using the usual method of the surgeon. The two conduits should be tacked together to prevent inadvertent torsion occurring.

The LAD territory should be grafted with the LIMA first, and sequential grafts performed to diagonal arteries as appear comfortable by draping the LIMA over the branches. This sequence is necessary to position the Y graft correctly, which should lie near to the lateral border of the pulmonary artery. If a hole was made in the pericardium to pass the conduits, the $\mathrm{Y}$ should be positioned near to this hole. The RA (or second IMA) should then be used to revascularize the circumflex and/or the right coronary territory by performing sequential anastomoses along its length from proximal to distal. The final anastomosis for each conduit is an end-to-side anastomosis.

If cardioplegic arrest is used, release of the conduit clamps may allow early reperfusion as well as optimal conditions for inspection of the anastomoses for leaks and for the lie of conduits.

Tips: The complexity of this operation is usually exaggerated; however, caution is advised during the early experience when using it for unstable patients, rescue situations or other factors that lead to additional 
independent stress for the surgeon. It is far better to become familiar with the technique under ideal or optimal circumstances, so that under urgent or non-optimal circumstances the methods are well practiced.

\section{Alternative combinations of graft reconstructions}

Many variants are described but these may be summarised as "mini-Y" grafts. Specifically, short lengths of conduits that may have been redundant from a previous aorta-coronary graft can be effectively utilised by creating a Y graft and using the conduit to graft a coronary artery with a more ideal lie. For example, a short length of IMA or RA could be sutured to the LIMA as a Y graft and used to graft a diagonal artery that was adopting a course widely divergent from the LAD, making a conventional sequential anastomosis with the main LIMA more difficult. Generally, more complex iterations of this technique do not facilitate ease of grafting.

Relatively common grafting configurations are depicted in Figure 8.

\section{Alternative conduits}

\section{Second internal mammary artery}

Use of a second internal mammary artery in composite grafting is discussed above. The alternative is the use of an in situ or RIMA. The key limitation of the in situ graft is the frequent inability to reach distal coronary targets. Devotees of the use of in situ graft usually claim that the PDA and sometimes the left ventricular branch, distal LAD or more distal marginal arteries can be reached; however, this is often not the case in the hands of many surgeons. The trajectory to the right coronary territory may be at risk of tension with excessive inflation of the lungs. Additionally, for circumflex territory targets, the trajectory of the RIMA may limit grafting by being constrained to passage through the transverse sinus or anterior to the ascending aorta to reach the LAD. For these left coronary vessel targets, the presence of a patent IMA graft in close proximity to the ascending aorta results poses a significant risk of inadvertent injury during redo surgery. Additionally, the meta-analysis data would suggest that, on balance, the risk of deep sternal wound infection with bilateral compared to unilateral IMA harvest roughly doubles ${ }^{[53-56]}$. The free graft is commonly believed to confer a lower patency compared to the in situ graft. However, this may be an anomaly of grafting strategy, as it is most commonly grafted to the RCA targets, or to circumflex targets of secondary importance. Therefore, when compared to LIMA-LAD grafts, the patency is lower, yet similar to other arterial grafts ${ }^{[100,101]}$. However, when a free IMA is grafted to the LAD, the survival is similar ${ }^{[102]}$. It is likely therefore that the higher patency of the LAD graft principally reflects the larger "run-off" of this vascular bed, compared to the conduit.

\section{Gastroepiploic artery}

The proponents are predominantly Japanese surgeons and advocate a pedicled over a free graft configuration $^{[87,103-107]}$. The reported complication rate of harvesting this conduit is low, but it is rarely used outside of Japan. The popular view internationally is that the harvest of this conduit is a major additional step to surgery and that the complication rate would be higher than for either SVG or RA harvest. Logically, this appears likely, especially with the higher obesity rates in Western countries, but there is very little direct evidence. The artery itself would be expected to behave in a similar manner to IMA or RA, by being resistant to the development of conduit atherosclerosis over the long term ${ }^{[103,108]}$.

\section{Degree of coronary stenosis and graft selection}

This topic is beyond the scope of this article. Competitive flow may affect all conduits and is present in all coronary territories. General observations are that the effects are greatest in the RCA territory and least in the LAD territory. For the surgeon early in their experience with multiple arterial grafting, it is wise to be conservative and graft lesions of high severity (e.g., $\geq 80 \%$ stenosis). The alternative to grafting should be not to graft, rather than grafting with SVG. 

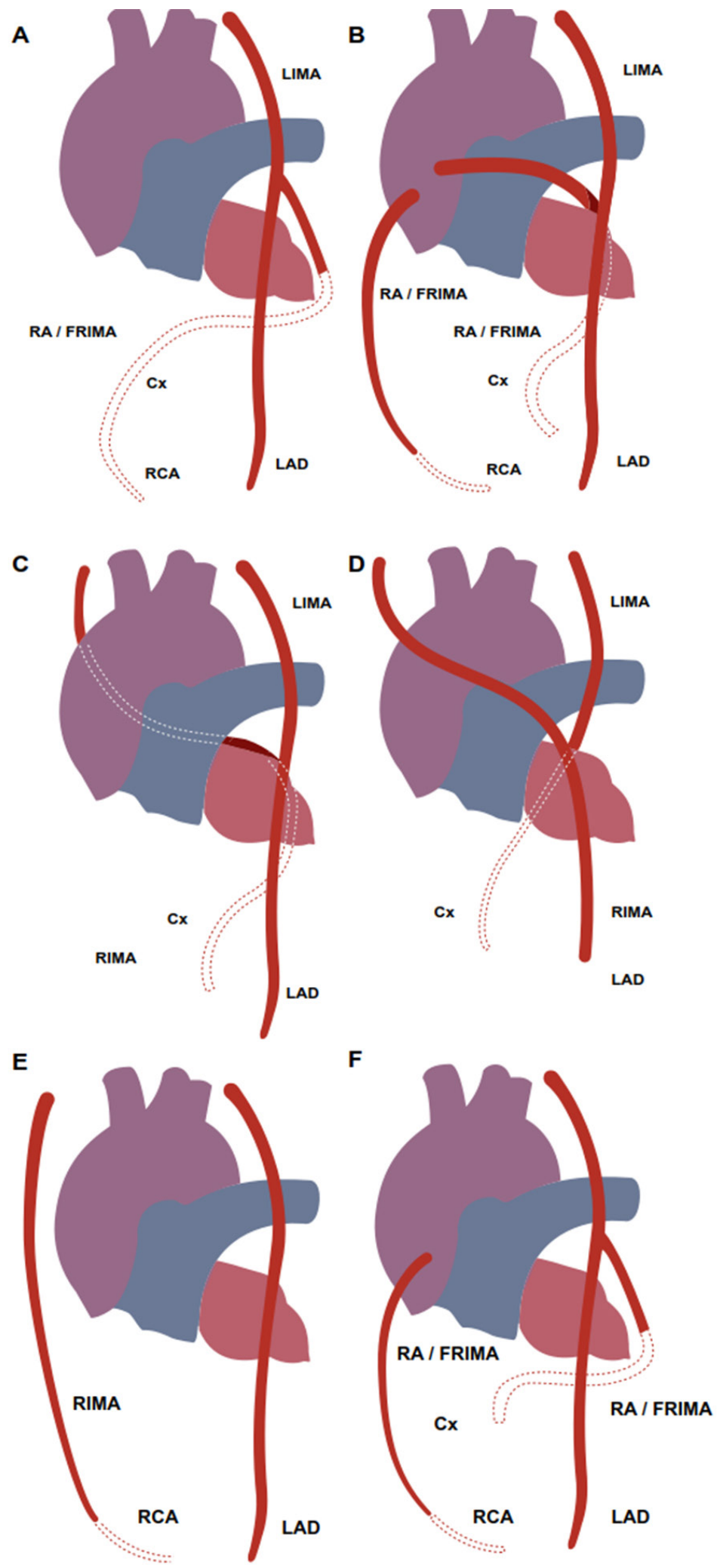

Figure 8. Commonly performed alternative grafting configurations achieving total arterial revascularisation: A: classical $Y$ graft; B: conventional grafting strategy (sequential grafting as required for each conduit within each coronary territory; C: in-situ RIMA to circumflex via transverse sinus; D: in-situ RIMA to LAD and LIMA to circumflex; E: in-situ RIMA to RCA territory; and F: "mini" $Y$ grafts from LIMA to left sided coronary targets, with additional aorta-coronary conduit for RCA territory. LIMA: left internal mammary artery; RIMA: right internal mammary artery; RA/FRIMA: radial artery or free right internal mammary artery; LAD: left anterior descending artery; Cx: circumflex; RCA: right coronary artery 
The effects of competitive flow are subject to some popular misconceptions:

1. Reduced arterial graft patency with reduced degree of coronary stenosis is not a "binary" phenomenon. Surgeons often assume that patency will be $100 \%$ when grafted to coronary lesions of more than a particular value (e.g., $80 \%$ or $90 \%$ stenosis) - and, conversely, they assume the patency will be $0 \%$ when grafted to lesions of less than this value. This is incorrect and exaggerated. The patency progressively diminishes as the degree of coronary stenosis decreases, and there is no specific cut-off value whereby patency falls to zero $^{[77,109-112]}$. In our as yet unpublished experience, the patency of all conduits exceeds $50 \%$ at angiography when grafted to coronary lesions of $\geq 50 \%$.

2. Use of SVG is resistant to the effects of competitive flow and can be used without adverse consequence for mild or moderate lesions. Our data indicate that even single SVG is associated with long-term adverse survival implications and we would advise avoidance of grafting with any conduit under these circumstances.

3. Early arterial graft failure from competitive flow is still a failure. From the clinical perspective, this is not true. The lack of a flow limiting coronary lesion (at rest) results in a minimal blood pressure drop distal to the lesion, and therefore a minimal pressure gradient driving flow across the conduit. The lack of conduit flow presumably leads to conduit ischemia, although the precise mechanism of arterial graft failure is unknown. Late histology of a string sign reveals a viable media and adventitia; however, the lumen is mostly obliterated with intimal hyperplasia. Because the target myocardium remains well supplied by blood at rest, there is no ischemic consequence to this graft failure.

4. A "string sign" (an angiographic appearance of severe and diffuse narrowing of an arterial conduit lumen, which does not fill the native coronary artery via the graft) is thought to be a reversible state. Many would believe that this is caused by spasm of the conduit (rather than the intimal hyperplasia seen at histology) and that relaxation of the conduit wall will reverse patency. We have never documented a case of reversal of string sign and consider it permanently occluded.

\section{FINAL WORD: BUYING INTO THE LEFT MAIN CORONARY STENOSIS PCI VS. CABG DEBATE}

Head et al. ${ }^{[113]}$ performed a patient level pooled analysis of 11 RCT examining PCI vs. CABG. The findings were of five-year all-cause mortality benefit for CABG (HR = 1.20, 95\%CI: 1.06-1.37, $P=0.004)$. However, the benefit was confined entirely to multivessel and complex coronary disease and in diabetic patients (HR $=1.28,95 \%$ CI: 1.09-1.49, $P=0.002)$. Non-diabetics and those with left main stenosis had no significant difference.

In late 2019, the five-year data for the EXCEL ${ }^{[114]}$ and $\operatorname{NOBLE}^{[115]}$ trials examining left main coronary stenosis of low and intermediate complexity were released. Great controversy surrounding the definition used for myocardial infarction (alleged to favour PCI) was ongoing at the time of this manuscript preparation. Nevertheless, these two trials reported apposing analyses using composite endpoints. The EXCEL trial reported no significant difference ( $\mathrm{HR}=1.19,95 \% \mathrm{CI}$ : $0.95-1.50, P=0.13$ ). The NOBLE trial reported superiority for CABG $(\mathrm{HR}=1.58,95 \% \mathrm{CI}: 1.24-2.01, P<0.001)$.

The key relevance to this manuscript is that none of the CABG vs. PCI trials accurately describe the revascularisation techniques of the CABG arm. Since the vast majority of patients are from North American or European centres, it is left to the reader to assume that the technique of CABG would closely reflect "routine" clinical practice in these regions. Specifically, it is therefore likely that the vast majority of patients undergoing $\mathrm{CABG}$ in these trials would have received a single arterial graft and supplementary SVG. What this suggests, is that the superiority of CABG over PCI in these trials - may be further magnified by a factor of at least 1.22 - if all of the CABG arm were to have received total arterial revascularisation.

It is therefore a matter of speculation as to whether PCI $v s$. CABG that is comprised entirely of total arterial 
revascularisation would demonstrate magnified significant differences, or converted non-significant to significant differences. There is a strong logical basis to propose new PCI $v s$. CABG (TAR) trials.

\section{CONCLUSION}

To increase the use of arterial grafts by initially substituting arterial conduits for venous conduits - but not altering the techniques of the surgeon - is a simple and pragmatic approach toward routine total arterial revascularisation. To achieve universal arterial graft use, a stepwise approach, practising the various sequential and Y graft methods, should be initially undertaken in elective and low risk surgery to minimise stress on the operating team.

\section{DECLARATIONS}

\section{Authors' contributions}

Authored this manuscript based on the work of many other studies and publications including manuscript design, writing, incorporation of prior analyses and of clinical opinion offered: Royse A

Co-authored all of the referenced studies and was involved in study design, execution and analysis in all: Royse C

Contributed to data collection and analysis in all of the studies referenced: Boggett S

Involved in the analysis of all of the studies referenced and co-written all: Clarke-Errey $S$

Involved in writing, data collection, data analysis and study design of the original study for the comparison of total arterial revascularisation and use of saphenous vein graft published in the European Journal of Cardiothoracic Surgery: Pawanis Z

\section{Availability of data and materials}

Not applicable.

\section{Financial support and sponsorship}

None.

\section{Conflicts of interest}

All authors declared that there are no conflicts of interest.

\section{Ethical approval and consent to participate}

Not applicable.

\section{Consent for publication}

Not applicable.

\section{Copyright}

(c) The Author(s) 2020 .

\section{REFERENCES}

1. Tabata M, Grab JD, Khalpey Z, Edwards FH, O’Brien SM, et al. Prevalence and variability of internal mammary artery graft use in contemporary multivessel coronary artery bypass graft surgery. Circulation 2009;120:935-40.

2. Bridgewater B, Keogh B, Kinsman R, Walton P. Sixth national adult cardiac surgical database report 2008. Oxfordshire: Dendrite Clinical Systems Limited; 2009.

3. Loop FD, Lytle BW, Cosgrove DM, Stewart RW, Goormastic M, et al. Influence of the internal-mammary-artery graft on 10-year survival and other cardiac events. N Engl J Med 1986;314:1-6.

4. Lytle BW, Loop FD, Cosgrove DM, Ratliff NB, Easley K, et al. Long-term (5 to 12 years) serial studies of internal mammary artery and saphenous vein coronary bypass grafts. J Thorac Cardiovasc Surg 1985;89:248-58. 
5. Lytle BW, Cosgrove DM, Loop FD, Borsh J, Goormastic M, et al. Perioperative risk of bilateral internal mammary artery grafting: analysis of 500 cases from 1971 to 1984. Circulation 1986;74:III37-41.

6. Sabik JF, Lytle BW, Blackstone EH, Houghtaling PL, Cosgrove DM. Comparison of saphenous vein and internal thoracic artery graft patency by coronary system. Ann Thorac Surg 2005;79:544-51.

7. Fitzgibbon GM, Kafka HP, Leach AJ, Keon WJ, Hooper GD, et al. Coronary bypass graft fate and patient outcome: Angiographic followup of 5,065 grafts related to survival and reoperation in 1,388 patients during 25 years. J Am Coll Cardiol 1996;28:616-26.

8. Grondin CM, Campeau L, Lespérance J, Enjalbert M, Bourassa MG. Comparison of late changes in internal mammary artery and saphenous vein grafts in two consecutive series of patients 10 years after operation. Circulation 1984;70:1208-12.

9. Bikdeli B, Hassantash SA, Pourabdollah M, Kalantarian S, Sadeghian M, et al. Histopathologic insight into saphenous vein bypass graft disease. Cardiology 2012;123:208-15.

10. Buckley BH, Hutchins GM. Accelerated "atherosclerosis." A morphologic study of 97 saphenous vein artery bypass grafts. Circulation 1977;55:163-9.

11. Davies MG, Hagen PO. Reprinted article "Pathophysiology of vein graft failure: a review". Eur J Vasc Endovasc Surg 2011;42:S19-29.

12. Hassantash SA, Bikdeli B, Kalantarian S, Sadeghian M, Afshar H. Pathophysiology of aortocoronary saphenous vein bypass graft disease. Asian Cardiovasc Thorac Ann 2008;16:331-6.

13. Lardenoye JHP, De Vries MR, LöWik CWGM, Xu Q, Dhore CR, et al. Accelerated atherosclerosis and calcification in vein grafts. Circ Res 2002;91:577-84.

14. Yahagi K, Kolodgie FD, Otsuka F, Finn AV, Davis HR, et al. Pathophysiology of native coronary, vein graft, and in-stent atherosclerosis. Nat Rev Cardiol 2016;13:79-98.

15. Weintraub WS, Grau-Sepulveda MV, Weiss JM, O'Brien SM, Peterson ED, et al. Comparative effectiveness of revascularization strategies. N Engl J Med 2012;366:1467-76.

16. Karthik S, Fabri BM. Left internal mammary artery usage in coronary artery bypass grafting: a measure of quality control. Ann R Coll Surg Engl 2006;88:367-9.

17. Campeau L, Enjalbert M, Lesperance J, Vaislic C, Grondin CM, et al. Atherosclerosis and late closure of aortocoronary saphenous vein grafts: sequential angiographic studies at 2 weeks, 1 year, 5 to 7 years, and 10 to 12 years after surgery. Circulation 1983;68:II1-7.

18. Goldman S, Zadina K, Moritz T, Ovitt T, Sethi G, et al. Long-term patency of saphenous vein and left internal mammary artery grafts after coronary artery bypass surgery: results from a Department of Veterans Affairs Cooperative Study. J Am Coll Cardiol 2004;44:2149-56.

19. Hata M, Yoshitake I, Wakui S, Unosawa S, Kimura H, et al. Long-term patency rate for radial artery vs. saphenous vein grafts using same-patient materials. Circ J 2011;75:1373-7.

20. FitzGibbon GM, Burton JR, Leach AJ. Coronary bypass graft fate: angiographic grading of 1400 consecutive grafts early after operation and of 1132 after one year. Circulation 1978;57:1070-74.

21. Kulik A, Voisine P, Mathieu P, Masters RG, Mesana TG, et al. Statin therapy and saphenous vein graft disease after coronary bypass surgery: analysis from the CASCADE randomized trial. Ann Thorac Surg 2011;92:1284-90.

22. Barner HB, Barnett MG. Fifteen- to twenty-one-year angiographic assessment of internal thoracic artery as a bypass conduit. Ann Thorac Surg 1994;57:1526-8.

23. Lytle BW, Blackstone EH, Sabik JF, Houghtaling P, Loop FD, et al. The effect of bilateral internal thoracic artery grafting on survival during 20 postoperative years. Ann Thorac Surg 2004;78:2005-12.

24. Yi G, Shine B, Rehman SM, Altman DG, Taggart DP. Effect of bilateral internal mammary artery grafts on long-term survival: a metaanalysis approach. Circulation 2014;130:539-45.

25. Adelborg K, Horváth-Puhó E, Schmidt M, Munch T, Pedersen L, et al. Thirty-Year mortality after coronary artery bypass graft surgery. Circ Cardiovasc Qual Outcomes 2017;10:e02708.

26. Otsuka F, Yahagi K, Sakakura K, Virmani R. Why is the mammary artery so special and what protects it from atherosclerosis? Ann Cardiothorac Surg 2013;2:519-26.

27. Shelton ME, Forman ME, Virmani R, Bajaj A, Stoney WS, et al. A comparison of morphologic and angiographic findings in long-term internal mammary artery and saphenous vein bypass grafts. J Am Coll Cardiol 1988;11:297-307.

28. Canham PB, Finlay HM, Boughner DR. Contrasting structure of the saphenous vein and internal mammary artery used as coronary bypass vessels. Cardiovasc Res 1997;34:557-67.

29. Galili O, Herrmann J, Woodrum J, Sattler KJ, Lerman LO, et al. Adventitial vasa vasorum heterogeneity among different vascular beds. J Vasc Surg 2004;40:529-35.

30. Acar C, Jebara VA, Portoghèse M, Fontaliran F, Dervanian P, et al. Comparative anatomy and histology of the radial artery and the internal thoracic artery. Implication for coronary artery bypass. Surg Radiol Anat 1991;13:283-8.

31. Baikoussis NG, Papakonstantinou NA, Apostolakis E. Radial artery as graft for coronary artery bypass surgery: advantages and disadvantages for its usage focused on structural and biological characteristics. J Cardiol 2014;63:321-8.

32. Chester AH, Marchbank AJ, Borland JA, Yacoub MH, Taggart DP. Comparison of the morphologic and vascular reactivity of the proximal and distal radial artery. Ann Thorac Surg 1998;66:1972-6.

33. Chowdhury UK, Airan B, Mishra PK, Kothari SS, Subramaniam GK, et al. Histopathology and morphometry of radial artery conduits: basic study and clinical application. Ann Thorac Surg 2004;78:1614-21.

34. Kerendi F, Halkos ME, Corvera JS, Kin H, Zhao ZQ, et al. Inhibition of myosin light chain kinase provides prolonged attenuation of radial artery vasospasm. Eur J Cardiothorac Surg 2004;26:1149-55.

35. Ruengsakulrach P, Sinclair R, Komeda M, Raman J, Gordon I, et al. Comparative histopathology of radial artery versus internal thoracic 
artery and risk factors for development of intimal hyperplasia and atherosclerosis. Circulation 1999;100:II139-44.

36. Tatoulis J, Buxton BF, Fuller JA, Royse AG. The radial artery as a graft for coronary revascularization: techniques and follow-up. In: Karp R, Lacks H, Weschler A, editors. Adv Card Surg. St Louis: Mosby; 1999. pp. 99-128.

37. Royse AG, Brennan AP, Ou-Young J, Pawanis Z, Canty DJ, et al. 21-year survival of left internal mammary artery-radial artery-Y graft. J Am Coll Cardiol 2018;72:1332-40.

38. Rocha RV, Tam DY, Karkhanis R, Nedadur R, Fang J, et al. Multiple arterial grafting is associated with better outcomes for coronary artery bypass grafting patients. Circulation 2018;138:2081-90.

39. Goldstone AB, Chiu P, Baiocchi M, Wang H, Lingala B, et al. Second arterial versus venous conduits for multivessel coronary artery bypass surgery in california. Circulation 2018;137:1698-707.

40. Gaudino M, Lorusso R, Rahouma M, Abouarab A, Tam DY, et al. Radial artery versus right internal thoracic artery versus saphenous vein as the second conduit for coronary artery bypass surgery: a network meta-analysis of clinical outcomes. J Am Heart Assoc 2019;8:e010839.

41. Taggart DP, Benedetto U, Gerry S, Altman DG, Gray AM, et al. Bilateral versus single internal-thoracic-artery grafts at 10 years. N Engl J Med 2019;380:437-46.

42. Royse A, Pawanis Z, Canty D, Ou-Young J, Eccleston D, et al. The effect on survival from the use of a saphenous vein graft during coronary bypass surgery: a large cohort study. Eur J Cardiothorac Surg 2018:54:1093-100.

43. Shi WY, Hayward PA, Fuller JA, Tatoulis J, Rosalion A, et al. Is the radial artery associated with improved survival in older patients undergoing coronary artery bypass grafting? An analysis of a multicentre experiencedagger. Eur J Cardiothorac Surg 2016;49:196-202.

44. Gaudino M, Benedetto U, Fremes S, Biondi-Zoccai G, Sedrakyan A, et al. Radial-artery or saphenous-vein grafts in coronary-artery bypass surgery. N Engl J Med 2018;378:2069-77.

45. Hata M, Seevanayagam S, Manson N, Rosalion A, Matalanis G, et al. Radial artery 2000--risk analysis of mortality for coronary bypass surgery with radial artery. Ann Thorac Cardiovasc Surg 2002;8:354-7.

46. Grover FL, Johnson RR, Marshall G, Hammermeister KE. Impact of mammary grafts on coronary bypass operative mortality and morbidity. Department of Veterans Affairs Cardiac Surgeons. Ann Thorac Surg 1994;57:559-68.

47. Royse A, Royse C, Groves K, Bartolo J. Is total arterial coronary revascularisation reducing operative mortality? Aust NZ J Surg. 1999;69:A16.

48. Tatoulis J, Buxton BF, Fuller JA, Royse AG. Total arterial coronary revascularization: techniques and results in 3,220 patients. Ann Thorac Surg 1999;68:2093-9.

49. Pandey R, Grayson AD, Pullan DM, Fabri BM, Dihmis WC. Total arterial revascularisation: effect of avoiding cardiopulmonary bypass on in-hospital mortality and morbidity in a propensity-matched cohort. Eur J Cardiothorac Surg 2005;27:94-8.

50. Lytle B, McElroy D, McCarthy P, Loop F, Taylor P, et al. Influence of arterial coronary bypass grafts on the mortality in coronary reoperations. J Thorac Cardiovasc Surg 1994;107:675-82.

51. Ioannidis JP, Galanos O, Katritsis D, Connery CP, Drossos GE, et al. Early mortality and morbidity of bilateral versus single internal thoracic artery revascularization: propensity and risk modeling. J Am Coll Cardiol 2001;37:521-8.

52. Kurlansky PA, Williams DB, Traad EA, Carrillo RG, Schor JS, et al. Arterial grafting results in reduced operative mortality and enhanced long-term quality of life in octogenarians. Ann Thorac Surg 2003;76:418-26.

53 Biancari F, Gatti G, Rosato S, Mariscalco G, Pappalardo A, et al. Preoperative risk stratification of deep sternal wound infection after coronary surgery. Infect Control Hosp Epidemiol 2020:1-8.

54. Deo SV, Shah IK, Dunlay SM, Erwin PJ, Locker C, et al. Bilateral internal thoracic artery harvest and deep sternal wound infection in diabetic patients. Ann Thorac Surg 2013;95:862-9.

55. Pevni D, Mohr R, Lev-Run O, Locer C, Paz Y, et al. Influence of bilateral skeletonized harvesting on occurrence of deep sternal wound infection in 1,000 consecutive patients undergoing bilateral internal thoracic artery grafting. Ann Surg 2003;237:277-80.

56. Borger M, Rao V, Weisel R, Ivanov J, Cohen G, et al. Deep sternal wound infection: risk factors and outcomes. Ann Thorac Surg 1998;65:1050-6.

57. Reyes AT, Frame R, Brodman RF. Technique for harvesting the radial artery as a coronary artery bypass graft. Ann Thorac Surg 1995;59:118-26.

58. Buxton B, Fuller J, Gaer J, Liu J, Mee J, et al. The radial artery as a bypass graft. Curr Opin Cardiol 1996;11:591-8.

59. Pola P, Serricchio M, Flore R, Manasse E, Favuzzi A, et al. Safe removal of the radial artery for myocardial revascularization: a Doppler study to prevent ischemic complications to the hand. J Thorac Cardiovasc Surg 1996;112:737-44.

60. Sudhakar CB, Forman DL, Dewar ML, Shaw RK, Fusi S. Free radial artery grafts: surgical technique and results. Ann Plast Surg 1998;40:408-11.

61. Royse A, Royse C, Shah P, Williams A, Kaushik S, et al. Radial artery harvest technique, use and functional outcome. Eur J Cardiothorac Surg 1999;15:186-93.

62. Royse AG, O’Donnell MJ, Mocioaca L, Sharma V, Ou-Young JC, et al. Does radial artery harvest for coronary surgery compromise forearm blood flow to 22 years post-operative? J Am Coll Cardiol 2018;72:1981-2.

63. Acar C, Jebara VA, Portoghese M, Beyssen B, Pagny JY, et al. Revival of the radial artery for coronary artery bypass grafting. Ann Thorac Surg 1992;54:652-9.

64. Gaudino M, Glieca F, Luciani N, Alessandrini F, Possati G. Clinical and angiographic effects of chronic calcium channel blocker therapy continued beyond first postoperative year in patients with radial artery grafts: results of a prospective randomized investigation. Circulation 2001;104:I64-7. 
65. Gaudino M, Luciani N, Nasso G, Salica A, Canosa C, et al. Is postoperative calcium channel blocker therapy needed in patients with radial artery grafts? J Thorac Cardiovasc Surg 2005;129:532-5.

66. Gaudino M, Benedetto U, Fremes SE, Hare DL, Hayward P, et al. Effect of calcium-channel blocker therapy on radial artery grafts after coronary bypass surgery. J Am Coll Cardiol 2019;73:2299-306.

67. Royse AG, Pawanis Z, Clarke-Errey S, Royse CF. Calcium-channel blockers and radial artery grafting. J Am Coll Cardiol 2019;74:1422.

68. Glineur D, Hanet C, D’Hoore W, Poncelet A, De Kerchove L, et al. Causes of non-functioning right internal mammary used in a Y-graft configuration: insight from a 6-month systematic angiographic trial. Eur J Cardiothorac Surg 2009;36:129-35.

69. Khot UN, Friedman DT, Pettersson G, Smedira NG, Li J, et al. Radial artery bypass grafts have an increased occurrence of angiographically severe stenosis and occlusion compared with left internal mammary arteries and saphenous vein grafts. Circulation 2004;109:2086-91.

70. Nakajima H, Kobayashi J, Tagusari O, Bando K, Niwaya K, et al. Competitive flow in arterial composite grafts and effect of graft arrangement in Off-Pump coronary revascularization. Ann Thorac Surg 2004;78:481-6.

71. Nakajima H, Kobayashi J, Toda K, Fujita T, Shimahara Y, et al. A 10-year angiographic follow-up of competitive flow in sequential and composite arterial grafts. Eur J Cardiothorac Surg 2011;40:399-404.

72. Nakajima H, Kobayashi J, Toda K, Fujita T, Shimahara Y, et al. Angiographic evaluation of flow distribution in sequential and composite arterial grafts for three vessel disease. Eur J Cardiothorac Surg 2012;41:763-9.

73. Paterson HS, Bannon PG. Composite Y grafts from the left internal mammary artery: current considerations. Heart Lung Circ 2018;27:133-7.

74. Yanagawa B, Verma S, Juni P, Tam DY, Mazine A, et al. A systematic review and meta-analysis of in situ versus composite bilateral internal thoracic artery grafting. J Thorac Cardiovasc Surg 2017;153:1108-16.e16.

75. Glineur D, Hanet C, Poncelet A, D’Hoore W, Funken JC, et al. Comparison of bilateral internal thoracic artery revascularization using in situ or Y graft configurations: a prospective randomized clinical, functional, and angiographic midterm evaluation. Circulation 2008;118:S216-21.

76. Hwang HY, Kim JS, Cho KR, Kim KB. Bilateral internal thoracic artery in situ versus y-composite graftings: five-year angiographic patency and long-term clinical outcomes. Ann Thorac Surg 2011;92:579-85.

77. Birkmeyer JD, Stukel TA, Siewers AE, Goodney PP, Wennberg DE, et al. Surgeon volume and operative mortality in the united states. N Engl J Med 2003;349:2117-27.

78. Finks JF, Osborne NH, Birkmeyer JD. Trends in hospital volume and operative mortality for high-risk surgery. N Engl J Med 2011;364:2128-37.

79. Glance LG, Dick AW, Mukamel DB, Osler TM. Is the hospital volume-mortality relationship in coronary artery bypass surgery the same for low-risk versus high-risk patients? Ann Thorac Surg 2003;76:1155-62.

80. Gutacker N, Bloor K, Cookson R, Gale CP, Maynard A, et al. Hospital surgical volumes and mortality after coronary artery bypass grafting: using international comparisons to determine a safe threshold. Health Serv Res 2017;52:863-78.

81. Díaz de Tuesta I, Cuenca J, Fresneda PC, Calleja M, Llorens R, et al. Volume-outcome relationship between surgical volume and mortality in cardiac surgery units in Spain. 2008;61:276-82. (in Spanish)

82. Ricciardi R, Virnig BA, Ogilvie JW Jr, Dahlberg PS, Selker HP, et al. Volume-outcome relationship for coronary artery bypass grafting in an era of decreasing volume. Arch Surg 2008;143:338-44.

83. Royse AG, Royse CF, Tatoulis J. Total arterial coronary revascularization and factors influencing in- hospital mortality. Eur J Cardiothorac Surg 1999;16:499-505.

84. Suzuki T, Asai T, Nota H, Kinoshita T, Fujino S. Impact of total arterial reconstruction on long-term mortality and morbidity: off-pump total arterial reconstruction versus non-total arterial reconstruction. Ann Thorac Surg 2015;100:2244-9.

85. Kobayashi J, Tagusari O, Bando K, Niwaya K, Nakajima H, et al. Total arterial off-pump coronary revascularization with only internal thoracic artery and composite radial artery grafts. Heart Surg Forum 2002;6:30-7.

86. Muneretto C, Negri A, Manfredi J, Terrini A, Rodella G, et al. Safety and usefulness of composite grafts for total arterial myocardial revascularization: a prospective randomized evaluation. J Thorac Cardiovasc Surg 2003;125:826-35.

87. Kamiya H, Watanabe G, Takemura H, Tomita S, Nagamine H, et al. Total arterial revascularization with composite skeletonized gastroepiploic artery graft in off-pump coronary artery bypass grafting. J Thorac Cardiovasc Surg 2004;127:1151-7.

88. Raja SG, Haider Z, Zaman H, Ahmed M. Total arterial myocardial revascularization: analysis of initial experience. Ann Saudi Med 2005;25:13-7.

89. Damgaard S, Lund JT, Lilleor NB, Perko MJ, Sander K, et al. Comparable three months' outcome of total arterial revascularization versus conventional coronary surgery: copenhagen arterial revascularization randomized patency and outcome trial. J Thorac Cardiovasc Surg 2008;135:1069-75.

90. Festinger L. Cognitive dissonance. Sci Am 1962;207:93-106.

91. Festinger L. A Theory of Cognitive Dissonance IL: Row, Peterson, Evanston; 1957.

92. McBride LR, Barner HB. The left internal mammary artery as a sequential graft to the left anterior descending system. J Thorac Cardiovasc Surg 1983;86:703-5.

93. Rammos KS, Koullias GJ, Pappou TJ, Bakas AJ, Panagopoulos PG, et al. A computer model for the prediction of left epicardial coronary blood flow in normal, stenotic and bypassed coronary arteries, by single or sequential grafting. Cardiovasc Surg 1998;6:635-48.

94. Glineur D, Etienne PY, Kuschner CE, Shaw RE, Ferrari G, et al. Bilateral internal mammary artery Y construct with multiple sequential grafting improves survival compared to bilateral internal mammary artery with additional vein grafts: 10 -year experience at 2 different 
institutionsdagger. Eur J Cardiothorac Surg 2017;51:368-75.

95. Royse AG, Royse CF, Raman JS. Exclusive Y graft operation for multivessel coronary revascularization. Ann Thorac Surg 1999;68:1612-8.

96. Tector AJ, Kress DC, Schmahl TM, Amundsen S. T-graft: a new method of coronary arterial revascularization. J Cardiovasc Surg (Torino) 1994;35:19-23.

97. Sundt TM, Barner HB, Camillo CJ, Gay WA Jr. Total arterial revascularization with an internal thoracic artery and radial artery T graft. Ann Thorac Surg 1999;68:399-404.

98. Wendler O, Hennen B, Markwirth T, Konig J, Tscholl D, et al. T grafts with the right internal thoracic artery to left internal thoracic artery versus the left internal thoracic artery and radial artery: flow dynamics in the internal thoracic artery main stem. J Thorac Cardiovasc Surg 1999;118:841-8.

99. Nicholson IA, Paterson HS. Modified T graft for triple-vessel disease. Ann Thorac Surg 1997;64:451-3.

100. Tatoulis J, Buxton B, Fuller J. Results of 1,454 free right internal thoracic artery-to-coronary artery grafts. Ann Thorac Surg 1997;64:1263-8.

101. Hayward PA, Hare DL, Gordon I, Matalanis G, Buxton BF. Which arterial conduit? Radial artery versus free right internal thoracic artery: six-year clinical results of a randomized controlled trial. Ann Thorac Surg 2007;84:493-7.

102. Raja SG, Benedetto U, Husain M, Soliman R, De Robertis F, et al. Does grafting of the left anterior descending artery with the in situ right internal thoracic artery have an impact on late outcomes in the context of bilateral internal thoracic artery usage? J Thorac Cardiovasc Surg 2014;148:1275-81.

103. Suma H. Gastroepiploic artery graft in coronary artery bypass grafting. Ann Cardiothorac Surg 2013;2:493-8.

104. Suma H, Tanabe H, Takahashi A, Horii T, Isomura T, et al. Twenty years experience with the gastroepiploic artery graft for CABG. Circulation 2007;116:I188-91.

105. Esaki J, Koshiji T, Okamoto M, Tsukashita M, Ikuno T, et al. Gastroepiploic artery grafting does not improve the late outcome in patients with bilateral internal thoracic artery grafting. Ann Thorac Surg 2007;83:1024-9.

106. Ryu SW, Ahn BH, Choo SJ, Na KJ, Ahn YK, et al. Skeletonized gastroepiploic artery as a composite graft for total arterial revascularization. Ann Thorac Surg 2005;80:118-23.

107. Tavilla G, Kappetein AP, Braun J, Gopie J, Tjien AT, et al. Long-term follow-up of coronary artery bypass grafting in three-vessel disease using exclusively pedicled bilateral internal thoracic and right gastroepiploic arteries. Ann Thorac Surg 2004;77:794-9.

108. Akita S, Tajima K, Kato W, Tanaka K, Goto Y, et al. The long-term patency of a gastroepiploic artery bypass graft deployed in a semiskeletonized fashion: predictors of patency. Interact Cardiovasc Thorac Surg 2019;28:868-75.

109. Juleff R, Brown O, McKain M, Glover J, Bendick P. The influence of competitive flow on graft patency. J Cardiovasc Surg (Torino) 1992;33:415-9.

110. Sabik JF, Lytle BW, Blackstone EH, Khan M, Houghtaling PL, et al. Does competitive flow reduce internal thoracic artery graft patency? Ann Thorac Surg 2003;76:1490-6.

111. Gaudino M, Massetti M, Farina P, Hanet C, Etienne PY, et al. Chronic competitive flow from a patent arterial or venous graft to the circumflex system does not impair the long-term patency of internal thoracic artery to left anterior descending grafts in patients with isolated predivisional left main disease: long-term angiographic results of 2 different revascularization strategies. J Thorac Cardiovasc Surg 2014;148:1856-9.

112. Paterson HS, Bannon PG, Taggart DP. Competitive flow in coronary bypass surgery: the roles of fractional flow reserve and arterial graft configuration. J Thorac Cardiovasc Surg 2017;154:1570-5.

113. Head SJ, Milojevic M, Daemen J, Ahn J-M, Boersma E, et al. Mortality after coronary artery bypass grafting versus percutaneous coronary intervention with stenting for coronary artery disease: a pooled analysis of individual patient data. Lancet 2018;391:939-48.

114. Stone GW, Kappetein AP, Sabik JF, Pocock SJ, Morice M-C, et al. Five-year outcomes after PCI or CABG for left main coronary disease. N Engl J Med 2019;381:1820-30.

115. Holm NR, Mäkikallio T, Lindsay MM, Spence MS, Erglis A, et al. Percutaneous coronary angioplasty versus coronary artery bypass grafting in the treatment of unprotected left main stenosis: updated 5-year outcomes from the randomised, non-inferiority NOBLE trial. Lancet 2020;395:191-9. 